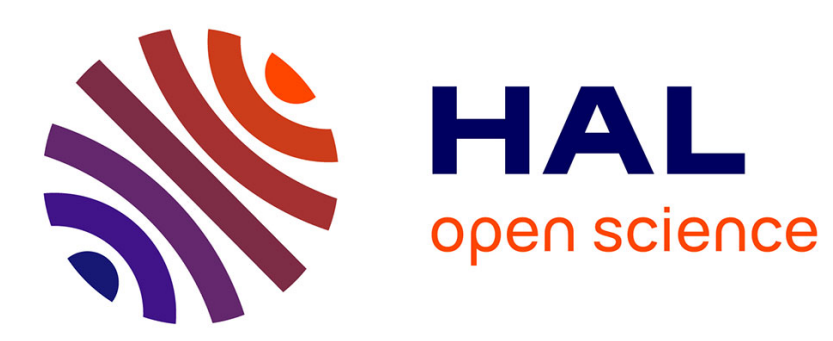

\title{
Optimized Workflow for the Healthcare Logistic: Case of the Pediatric Emergency Department
}

\author{
Ines Ajmi, Hayfa Zgaya, Slim Hammadi
}

\section{To cite this version:}

Ines Ajmi, Hayfa Zgaya, Slim Hammadi. Optimized Workflow for the Healthcare Logistic: Case of the Pediatric Emergency Department. 7th International Conference on Practical Applications of Computational Biology \& Bioinformatics, May 2013, Salamanca, Spain. hal-01716929

\section{HAL Id: hal-01716929 \\ https://hal.science/hal-01716929}

Submitted on 6 Mar 2018

HAL is a multi-disciplinary open access archive for the deposit and dissemination of scientific research documents, whether they are published or not. The documents may come from teaching and research institutions in France or abroad, or from public or private research centers.
L'archive ouverte pluridisciplinaire HAL, est destinée au dépôt et à la diffusion de documents scientifiques de niveau recherche, publiés ou non, émanant des établissements d'enseignement et de recherche français ou étrangers, des laboratoires publics ou privés. 


\title{
Optimized Workflow for the healthcare logistic: Case of the Pediatric Emergency Department
}

\author{
Inès Ajmi $^{(a)}$, Hayfa Zgaya ${ }^{(b)}$, Slim Hammadi (a) \\ (a) LAGIS/EC-Lille UMR CNRS 8219, ${ }^{\text {(b) }}$ EA 2694, Laboratory of Public Health
}

\begin{abstract}
The Emergency Department (ED) in a hospital, as its name implies, is a facility to be utilized by those who require emergency medical care. This paper introduces the longitudinal organization of the patient handling" in the Pediatric Emergency called the "Pediatric Emergency Path". This work discusses the usability of the workflow approach in order to design the patient path in the Pediatric Emergency Department (PED) in order to thwart the care complexity scheme. The goal is to optimize these paths to improve the quality of the patient handling while mastering the wait time. The development of this model was based on accurate visits made in the PED of the Regional University Hospital Center (CHRU) of Lille (France). This modeling, which has to represent most faithfully possible the reality of the PED of CHRU of Lille, is necessary. It must be enough retailed to produce an analysis allowing to identify the dysfunctions of the PED and also to propose and to estimate prevention indicators of tensions. Our survey is integrated into the French National Research Agency project, titled: "Hospital: optimization, simulation and avoidance of strain" (ANR HOST) ${ }^{1}$.
\end{abstract}

Keywords PED, workflow, modeling, peak of activity, tension indicators.

\section{Introduction}

In France, as in many countries of Europe, the emergency departments present the same difficulties whose reasons are multiple. These difficulties are not only linked to the health organization but also to the evolution of the western civilization [1]. The requirements concerning health care evolved in relation with a new approach to management of the time. Today, people require a fast and efficient handling. They reject the ageing, the illness and the death [2]. The arrival patient flow to the emergency department keeps increasing. This rise has generated a strategic interest in optimizing the technical and human resources while mastering the costs [3]. In order to reach these objectives, the health establishments have resorted to the tools and techniques of management borrowed from the industry domain [4] as the Workflow tool that will be used in this article. The use of Workflow methodology showed applicability and the interest of the company modeling method to reorgan-

\footnotetext{
${ }^{1}$ ANR-11-TecSan-010
} 
ize a health establishment. It allowed improving the performance of different service and activities conduct system [4]. The Discrete Event Simulation (DES) techniques have been used a lot for modeling the operations of an Emergency Department (ED). The model was developed to test alternative ED attending physicianstaffing schedules and to analyze the corresponding impacts on patient throughput and resource utilization [5], to help the ED managers understand the behavior of the system with regard to the hidden causes of excessive waiting times [6], to analyze patient flows and throughput time [7] [8][9][10]. DES has also been used for estimating future capacities of new ED facilities or expansions [11] [12]. The main objectives of the present paper are: 1) To model the Pediatric Emergency Department (PED) using Workflow Methodology for better understanding the patient flow process through the PED, 2) To simulate using the same tool Workflow in order to identify and analysis the dysfunctions of the PED and also to propose and to estimate prevention indicators of tensions.

This article is structured in five sections. The first one presents the context of the survey. We introduce the notion of "Emergency Path" in section two. In the third section, we explain the workflow modeling at the PED Section four describes the simulation model and some experiments and results. Finally in section five we draw the conclusions of this work.

\section{Context of survey}

The health system is characterized by an increasing complexity which requires the performance and the mastery of the costs, and so comes the necessity to have new tools in support of the management strategy. This problematic has generated the idea of the HOST ANR national project in the PED which has the objective to elaborate a new methodological approach for the anticipation of the tensions of the complex care production system and more especially of the emergency paths. The problematic of strategy, the performance assessment and traceability of the patient course are integrated into the approaches which are suggested. The HOST ANR national project is a scientific research work in the hospital world with fallouts for the PED of the CHRU of Lille.

The scientific fallouts expected of this project are:

- A prospective vision of the conception and the piloting of global emergency activity handling system in European context.

- A good tool to anticipate the tensions of the PED.

- The fallouts for emergency paths actors will consist in establishing the methods and operational tools allowing:

- To bring the recommendations for the emergency paths conception and reengineering for health establishments,

- To improve the handling efficiency and the quality of the service returned to the patient,

- To assure a better internal and external coordination with the other actors of the emergency path when the tensions can't be avoided. 
- To permit best practices sharing.

Our work represents the first step of the national ANR HOST project realization and discusses the emergency handling system. The ubiquity of the emergency problem in France and in Europe, the strategic place of the ED in the health establishments, the frequency and the huge media coverage of the dissatisfaction of the ED users and rising health care costs are primarily responsible for the high level of interest in PED. The PED of the CHRU of Lille nursing staff constituted by physicians, surgeons, senior executives, nurses...etc. and administrative staffs of the CHRU of Lille are implied in our survey. The direction of the quality, strategy, and the medical information participate in the realization of this work.

\section{The emergency path in the PED}

Emergency Path is a longitudinal organization of the patient's handling. It is not a structure but an operative concept. The patient flow can vary from patient to patient based on acuity level and diagnosis [12]. The hospital establishments are chronically confronted to a problematic for which no satisfying answer exists at the present time. This problematic is resulting from the permanent interferences between the programmed and the non-programmed activity, and more especially the urgent non programmed activity. We can define two operational concepts that will intervene in the description of the PED: 1) The incoming flows: programmed or non-programmed, with almost periodic or uncertain variation, 2) The retiring flows: constituting the downstream of the PED. The emergency path, the incoming and the retiring flows are three concepts that describe the PED like a complex system in interaction. We proceeded to the modeling of the survey project at the PED of the CHRU of Lille. The phases of Workflow of the PED modeling are:

- Description of the features of each element of the global process and its subprocesses in the PED,

- Modeling the PED (flow and resources organization) and its interactions with the other internal components of the CHRU of Lille,

- To define a typology of the patients admitted in the PED of the CHRU of Lille.

\section{The PED workflow modeling}

The main objective of our survey is to identify the dysfunctions of the PED and also to propose and to estimate prevention indicators of tensions. To reach this objective, it is necessary to have a global Workflow model of the PED and its environment. Before optimizing and simulation of the PED, it is necessary to analyze and to characterize the PED structure. It requires the use of Workflow methodology to represent the functional and process view of the PED and its related parts.

\subsection{The PED of the CHRU of Lille}

The term of emergency covers two distinct phenomena:

- The recurrent flows are able to present some seasonal variations, but known on average on middle horizons (i.e. month or year). Even, if these flows are feared, quantified in volume and in nature on medium and short term, the set- 
ting up of a structure, an organization and a piloting is a major stake of efficiency of the care production.

- The flows following upon the sanitary crises (flow, heat waves, cold weather waves). In this case, the flows are completely unforeseen in volume and in nature.

The adaptation and the implementation of organization, scheduling, management and optimization approved methods are foreseeable for the programmed patients flows handling, but it is a lot more complex to master the emergency flows handlings. The problem is not simple because today the emergencies are considered by the actors of the health system themselves as main entropy generator of the cares system.

\subsection{The workflow methodology}

To model the health system, a lot of company modeling methods has been used. The company modeling is the representation of the enterprise in terms of strategy, structure, functionalities, behavior, organization, evolution and relations with the environment. One of these methods is the Workflow methodology. It has been used for modeling, diagnosis and conception of a hospital system [13]. This work permitted to demonstrate applicability and the interest of the company modeling methods to reorganize a health establishment. The objective of the development and description of the workflow model is to assess the overall processing capabilities of the flow in order to support various joint activities between medical staff that is temporally and spatially dispersed. Control of the workflow for the purpose of optimizing the placement of limited medical resources, both personnel and equipment, on the medical scene is an important issue. Since typical unforeseen circumstances will frequently occur in the PED environment, there is a need for an effective model, capable of dynamic control in workflow descriptions, for medical treatment. Thus, for descriptions of the workflow in this paper, we have used the BPMN standard graphical language, which is easy for users to express and is readily comprehensible [14].

\subsection{The phase of modeling}

We are going to model all paths exist at PED of the CHRU Lille. We are going to represent the physical system service and the PED to have a complete idea of the patient flows. In this paper, we start with the representation of the physical system in the PED and the emergency paths of External care, Unit of short term hospitalization and Care emergency vital. We represent only the models that will be analyzed after modeling the whole paths of the PED of the CHRU Lille in the ulterior stages of our survey. The physical systems of the PED and the emergency paths that we have just mentioned previously are represented by the figures 1, 2, 3 and 4 . The set of the functional models presented in this paper have been achieved with the Bonita soft software Workflow. We remark that these models are characterized by the diversity of the activities and the big number of people that intervenes in the patient handling process and its diagnosis nature. We note in more the uncer- 
tain criteria in the patients handling and the risks that can emerge during his path. The aggravation of a patient's state can already stimulate the change of his cares process anticipated. It confirms us the complexity of the emergency handling system. It is also interesting to see that some activities of these processes are decisional. These decisions are not management decisions but the choices in the patient [15] (Care traditional hospitalization, external care, Unit of short term hospitalization, Care as a matter of emergency vital, Consultation in a cubicle).

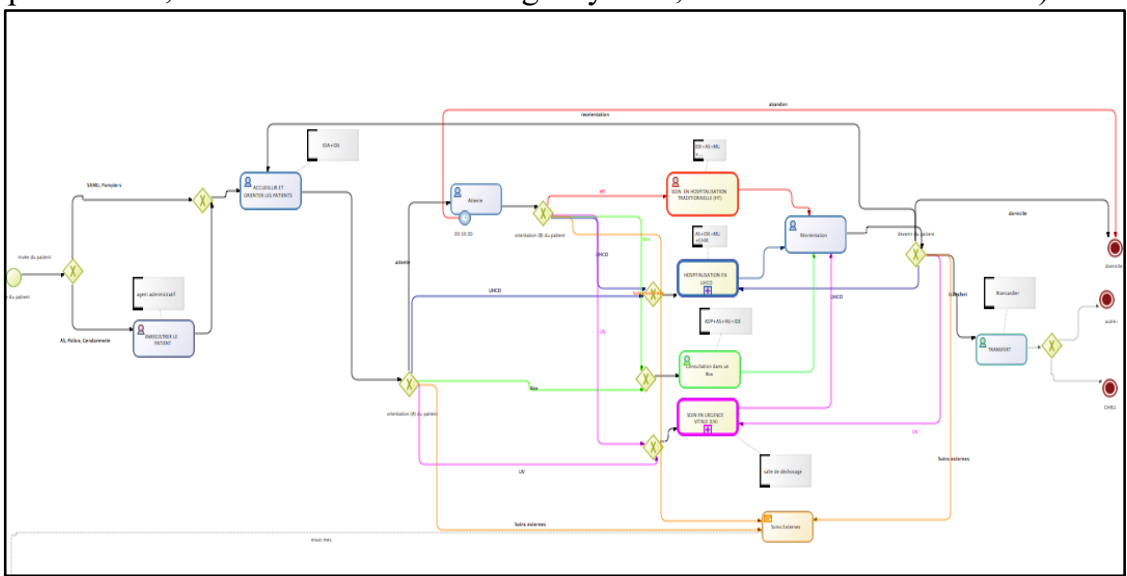

\section{Emergency department simulations}

After modeling the emergency department, we intend to use discrete event simulation techniques to conceive a simulation model which is comprehensible, flexible, and easy for use and representative of the reality. Since, we consider using this model in the ulterior stages of our solution and to adapt it to the different patient emergency paths (Care traditional hospitalization, external care, Unit of short term hospitalization, Care as a matter of emergency vital, Consultation in a cubicle).

\subsection{The data analysis}

To do the simulations, we need the patients' information. We could collect some information at the PED of CHRU Lille which allowed studying the different features of the patient

\subsubsection{The sex}

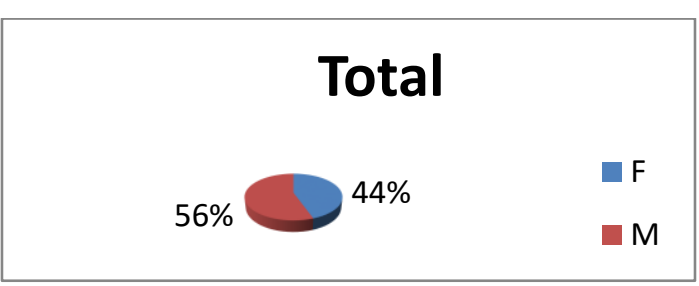

\subsubsection{The arrival flow of patient at the PDE}




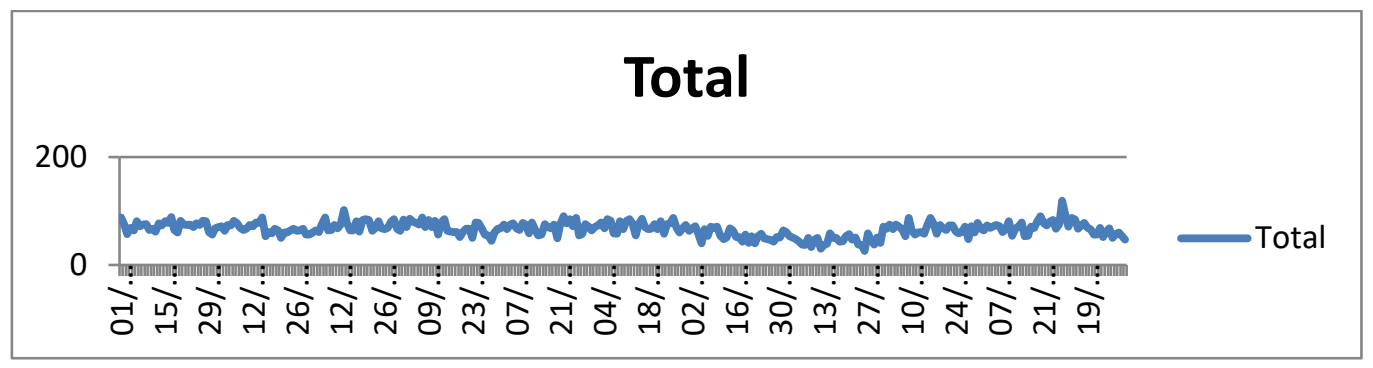

\subsubsection{The arrival types at the PED}

\begin{tabular}{|l|} 
Total \\
\\
\end{tabular}

\subsubsection{The age}

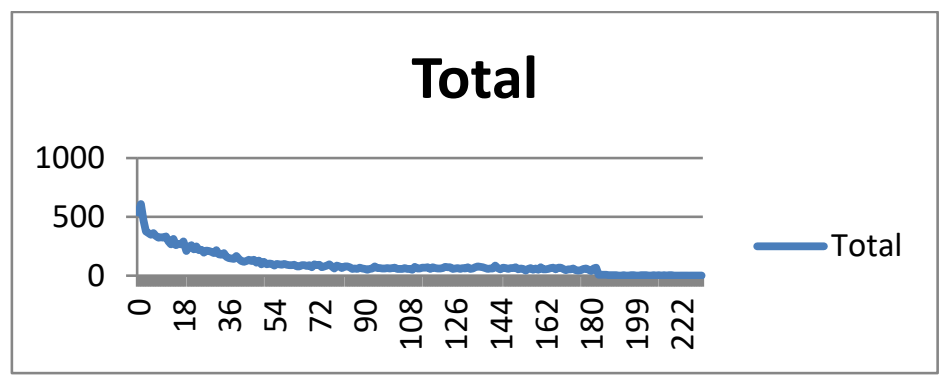

\subsection{Experiments and results}

For a simulation on last year, the main gotten results are presented in Table I simulation results and Table II global statistics. It is possible to look at other numerous statistics but it would constitute a deeper analysis that will be treated in the ulterior stages of our survey. 


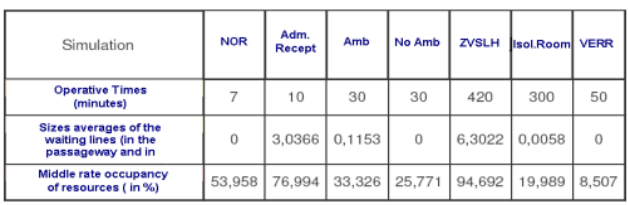

TABLE I: simulation results

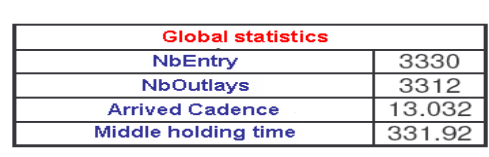

TABLE II: global statistics

\section{Conclusion and prospects}

In this paper, we presented the setting of our survey that will last two years in the PED of CHRU Lille, the first step of the modeling phase of the patient handling system in the PED and the PED simulation .This first step allowed us to conclude that the simulation model developed in this paper can be used to help identify process inefficiencies and to evaluate the effects of layout, staffing, resource and patient flow changes on system performance. In the ulterior stages of this survey, we are going to model the totality of the emergency paths in the PED of CHRU of Lille, to analyze the gotten models and to conceive a complete model of the patient handling system. We are going to achieve a simulation of these models to value the modeling system performances (percentage occupancy of resources, service quality indicators).

\section{References}

[1] A.Reix., "Etude de l'organisation des différents systèmes d'urgence dans six pays euro-péens : La France, le Royaume Uni, la Belgique, la Suède, la Finlande et la Norvège" (2002) Memory of thesis for the diplôma of doctor state in medicine : 18

[2] M.Chodosas., "Etude de l'organisation des différents systèmes d'urgence dans cinq pays européens (2002) La France, l'Allemagne, l'Espagne, l'Italie et le Portugal ", Mémoire de thèse pour le doctorat en médecine: 20

[3] J-F.Navas, C.Artéta, P.S.Hadjes, F.Jiménez (2003) « Construction et simulation d'un modèle de fluxde patients dans le service d'urgences d'un hôpital colombien «, Formato de Atencion Inicial de Urgencias, en « Procesos Operativos de Urgencias », Documentos confidenciales Servicio de Urgencias Fundacion Cardiolnfantil, Agosto

[4] Y.Ducq, B.Vallespir, G.Doumeingts, "Utilisation de la méthodologie GRAI pour la modé-lisation, le diagnostic et la conception d'un système hospitalier ", GISEH.

[5] M .D.Rossetti, G.F.Trzcinski, S.A.Syverud, "Emergency department simulation and de-termination of optimal attending physician staffing schedules", In Proceeding of the 1999 Winetr Simulation Conference, P.A. Farrington , H.B.nembhard, D.T.Sturrock,and G.W.Evands,eds. 
[6] B.E. Ruby, S.W. Darrell, A.S. Wendy and H.C. Mary, "The use of simulation to evaluate hospital operations between the emergency department and a medical telemetry unit", In Pro-ceedingsof the 2003 Winter Simulation Conference, S.Chick, P. J. Sanchez, D. Ferrin, and D. J. Morrice (eds), 1887-1893.

[7] Samaha Simon, Armel S. Wendy and Starks W. Darrell (2003) "The use of simulation to reduce the length of stay in an emergency department", In Proceedings ofthe 2003 Winter Simu-lation Conference, S. Chick, P. J.Sanchez, D. Ferrin, and D. J. Morrice (eds): 1907-1911.

[8] Mahapatra S., Koelling C. P., Patvivatsiri L., Fraticelli B.Eitel D., and Grove L (2003) "Pairing emergency severity index5-level triage data with computer aided system design to im-prove emergency department access and throughput", In Proceedings of the 2003 Winter Simula-tion Conference, S. Chick, P. J. Sanchez, D.Ferrin, and D. J. Morrice (eds): 1917-1925.

[9] Takakuwa Soemon and Shiozaki Hiroko (2004) "Functional analysis for operating emer-gency department of a general hospital",In Proceedings of the 2004 Winter Simulation Confer-ence, R. G. Ingalls, M. D. Rossetti, J. S.Smith, and B. A. Peters (eds): 2003-2011.

[10] Baesler F. Felipe, Jahnsen E. Hector and Da Costa Mahal (2003) "The use of simulation and design of experiments for estimating maximum capacity in an emergency room", In Proceedings of the 2003 Winter Simulation Conference, S. Chick, P. J. Sanchez, D. Ferrin, and D.J. Morrice (eds): 1903-1906.

[11] Wiinamaki Allan and Dronzek Rainer (2003) "Using simulation in the architectural concept phase of an emergency department design", In Proceedings of the 2003Winter Simulation Conference, S. Chick, P. J. Sanchez, D. Ferrin, and D. J. Morrice (eds): 1912-1916.

[12] M .D.Rossetti, G.F.Trzcinski, S.A.Syverud, "Emergency department simulation and de-termination of optimal attending physician staffing schedules", In Proceeding of the 1999 Winetr Simulation Conference, P.A. Farrington, H.B.nembhard, D.T.Sturrock, and G.W.Evands,eds.

[13] N-B. Souf, J-M. Renard, Régis (1999) "Dynamic workflow model for complex activity in intensive care unit", In international journal of Medical Informatics 53 : 143-150 Lille-France

[14] A.Komashie, A.Mousavi (2005) "Modeling emergency departments using Discrete Event Simulation techniques ", In Proceeding of the 2005 Winter Simulation Conference, M. E. Kuhl, N. M. Steiger, F. B. Armstrong, and J. A. Joines, eds.

[15] A. Fraisse, S. Le Bel, B.Mas, D. Macrae (2010) Paediatric cardiac intensive care unit: Current setting and organization, science direct: 546-551 Marseille France 